\title{
Autonomic modulation at rest and in response to postural change in adolescents with Duchenne muscular dystrophy: a cross- sectional study
}

\author{
Modulação autonômica em repouso e em resposta a mudanças posturais em \\ adolescentes com distrofia muscular de Duchenne: um estudo transversal \\ Mariana Viana RODRIGUES ${ }^{1}$, Mileide Cristina STOCO-OLIVEIRA', Talita Dias da SILVA², Celso FERREIRA², \\ Heloisa Balotari VALENTE1', Laís Manata VANZELLA', Luiz Carlos Marques VANDERLEI ${ }^{1}$
}

\begin{abstract}
Background: Analysis of autonomic modulation after postural change may inform the prognosis and guide treatment in different populations. However, this has been insufficiently explored among adolescents with Duchenne muscular dystrophy (DMD). Objective: To investigate autonomic modulation at rest and in response to an active sitting test (AST) among adolescents with DMD. Methods: Fifty-nine adolescents were included in the study and divided into two groups: 1) DMD group: adolescents diagnosed with DMD; 2) control group (CG): healthy adolescents. Participants' weight and height were assessed. Lower limb function, motor limitations and functional abilities of the participants in the DMD group were classified using the Vignos scale, Egen classification and motor function measurement, respectively. The following variables were assessed before, during and after AST: systolic blood pressure (SBP), diastolic blood pressure (DBP), respiratory rate (f), oxygen saturation and heart rate (HR). To analyze the autonomic modulation, the HR was recorded beat-by-beat. Heart rate variability (HRV) indices were calculated in the time and frequency domains. Results: Differences in relation to groups were observed for all HRV indices, except LF/HF, oxygen saturation, HR and $f(p<0.05)$. Differences in relation to time and the interaction effect between group and time were observed for RMSSD, SD1, SD2, SD1/SD2, LFms ${ }^{2}$ and LFnu, HFun, SBP and DBP ( $p<0.05$ ). Differences in relation to time were also observed for the indice SDNN, FC and $f(p<0.05)$. Conclusions: Performing the AST promoted reduced autonomic modulation and increased SBP, DBP and HR in adolescents with DMD.
\end{abstract}

Keywords: Muscular Dystrophy, Duchenne; Heart Rate; Autonomic Nervous System Diseases; Posture.

\begin{abstract}
RESUMO
Antecedentes: A análise da modulação autonômica após mudanças posturais pode gerar informações prognósticas e orientar o tratamento em diferentes populações. Porém, isso não foi suficientemente explorado em adolescentes com DMD. Objetivo: Investigar a modulação autonômica em repouso e em resposta ao teste ativo sentado (TAS) em adolescentes com DMD. Métodos: 59 adolescentes foram incluídos no estudo e divididos em dois grupos: 1) Grupo DMD: adolescentes com diagnóstico de DMD; 2) Grupo controle: adolescentes saudáveis. O peso e a altura dos participantes foram avaliados. No grupo DMD, a funcionalidade de membros superiores, limitações motoras, e habilidades funcionais foram classificadas pela escala de Vignos, Egen Klassification, e motor function measure respectivamente. Pressão arterial sistólica (PAS), pressão arterial diastólica (PAD), frequência respiratória (f), saturação de oxigênio, e frequência cardíaca (FC) foram avaliadas em repouso, durante e após o TAS. Para analisar a modulação autonômica, a FC foi registrada batimento a batimento. Os índices de variabilidade da frequência cardíaca (VFC) foram calculados nos domínios do tempo e da frequência. Resultados: Diferenças entre os grupos foram observadas para todos os índices da VFC, exceto LF/HF, saturação de oxigênio, FC e f (p<0,05). Diferenças em relação ao tempo e interação entre grupo e tempo foram observadas para RMSSD, SD1, SD2, SD1/SD2, LFms², LFun, HFnu, SBP e DBP (p<0,05). Diferenças em relação ao tempo foram também observadas para o índice SDNN, FC e f $(p<0,05)$. Conclusões: A realização do TAS promoveu redução da modulação autonômica e aumento da PAS, PAD e FC em adolescentes com DMD.
\end{abstract}

Palavras-chave: Distrofia Muscular de Duchenne; Frequência Cardíaca; Doenças do Sistema Nervoso Autônomo; Postura.

${ }^{1}$ Universidade Estadual Paulista, Faculdade de Ciências e Tecnologia, Presidente Prudente SP, Brazil.

¿Universidade Federal de São Paulo, Escola Paulista de Medicina, São Paulo SP, Brazil.

MVR (iD https://orcid.org/0000-0003-0055-1294; MCSO (iD https://orcid.org/0000-0002-8685-2786; TDS (D) https://orcid.org/0000-0002-4683-4671; CF (iD https://orcid.org/0000-0001-9032-9624; HBV (D) https://orcid.org/0000-0003-3975-1904; LMV (DD https://orcid.org/0000-0002-9494-3143; LCMV (iD) https://orcid.org/0000-0002-1891-3153

Correspondence: Laís Manata Vanzella; Email: Laismv@hotmail.com.

Conflicts of interest: There is no conflict of interest to declare.

Authors' contributions: All authors contributed to the conception, design and data curation, commented on previous versions of the manuscript, read and approved the final version of this manuscript; MVR, MCSO, HBV: contributed to data collection and methodology; LMV, CF, LCM: contributed to the methodology; LMV, TDS: analysis and interpretation of data; MVR: white the manuscript; LCM: contributed to the investigation, project administration and supervision of the study.

Received on September 26, 2020; Received in its final form on November 24, 2020; Accepted on January 06, 2021. 


\section{INTRODUCTION}

Duchenne muscular dystrophy (DMD) is a progressive neuromuscular disease affecting approximately 1 in 3500 newborn males ${ }^{1,2}$. DMD affects not only the neuromuscular systems but also the cardiac, respiratory and autonomic system $^{3-6}$. Progressive cardiac disorders are considered to be one of the major causes of premature death among individuals with DMD. These disorders are reflected in poor prognoses and increased mortality rates in this population?

Autonomic nervous system (ANS) dysfunction is also observed in individuals with DMD. It can be assessed using heart rate variability (HRV), a noninvasive method in which the ANS is assessed based on fluctuations in the time intervals between consecutive heartbeats (RR intervals) (., $^{8,}$. Increased sympathetic modulation is observed in individuals with DMD. Although autonomic sympathetic modulation is identified from the outset of the disease, there is evidence to suggest that it increases with individuals' increasing age and severity of $\mathrm{DMD}^{9}$. Over a long-term perspective, increased sympathetic modulation and reduced HRV are associated with worse cardiac and pulmonary function. Thus, analysis of the ANS in this population may be considered to provide an important preclinical marker of cardiovascular complications and sudden death'.

Autonomic dysfunctions is identified by the HRV either at rest or during postural change tests, such as the active sitting test, which consists of a postural change from the supine to a sitting position ${ }^{10}$ The aim of this test is to stimulate the ANS by increasing the sympathetic autonomic modulation, heart rate (HR) and blood pressure (BP) and decreasing the parasympathetic autonomic modulation ${ }^{11} \mathrm{An}$ increase in $\mathrm{HR}$ and decrease in systolic BP have been observed in response to the active sitting test performed by individuals with DMD. However, the literature is sparse with regard to the responses of the ANS to the active sitting test, performed by this population.

Postural change commonly occurs during therapeutic interventions for individuals with DMD. The association between HRV and the active sitting test may be an important combination for assessing autonomic modulation in individuals with DMD. It may lead to identification of possible symptoms occurring in therapeutic sessions and guide providers to a more efficient and more adequate therapeutic intervention for this population.

Hence, the aim of the present study was to evaluate the autonomic modulation and cardiorespiratory parameters of adolescents with DMD, at rest and in response to the active sitting test. We hypothesized that the autonomic modulation would be reduced and the cardiorespiratory parameters would be increased in response to the active sitting test performed by adolescents with DMD, in comparison with healthy adolescents.

\section{METHODS}

\section{Participants}

A total of 28 adolescents with a medical diagnosis of DMD (DMD group) and 31 healthy adolescents with typical development (control group, CG) completed the tests of this study. For both the CG and the DMD, the inclusion criteria were that the participants should be male adolescents, aged 11 to 17 years. Adolescents with cardiac arrhythmias, under medication with atrioventricular blockers, with congenital heart diseases, with pulmonary malformations or using medicines influencing the HR were not included in the study. Participants with more than 5\% error in the HRV data recorded were withdrawn from the study.

Before the beginning of the study, the parents or legal guardian of each participant were asked to sign an informed consent statement. Then, each adolescent aged 11 to 17 years old was asked to sign an assent statement. This study was approved by the Research Ethics Committee of the São Paulo State University, School of Technology and Sciences, Presidente Prudente, São Paulo, Brazil.

\section{Study design}

In line with the study objective, HRV and cardiorespiratory parameters were assessed in both groups (DMD and CG). HRV was assessed before and during the active sitting test. The patients remained at rest in the supine position for 20 minutes and then changed to a sitting position for 5 minutes, to complete the test. The participants' HR was recorded beat-by-beat before and during the activity sitting test. Cardiorespiratory parameters such as systolic blood pressure (SBP), diastolic blood pressure (DBP), HR, respiratory rate ( $\mathrm{f}$ ) and oxygen saturation were assessed before, during and after the active sitting test.

To characterize the sample, the participants' body mass index (BMI) was calculated according to the formula: BMI = weight $(\mathrm{kg}) /$ height $(\mathrm{m})^{2}$. In the DMD, lower-limb function was assessed using the Vignos scale ${ }^{12}$, motor limitation was assessed using the Egen classification $(\mathrm{EK})^{13}$ and functional abilities were assessed by using the motor function measurement $(\mathrm{MFM})^{14}$.

\section{Vignos scale}

The Vignos scale aims to assess individuals' lower-limb function. It is commonly used to grade the stages of DMD, and measures aspects of walking, climbing stairs and sitting on a chair. The score ranges from $0-10$. Lower scores represent greater lower-limb function ${ }^{12}$.

\section{Egen classification (EK)}

The EK classifies individuals' motor limitation at advanced stages of the disease. It assesses individuals' ability to control a wheelchair, transfer to a wheelchair, stand up, sit down, use 
their arms, use their hands to eat, roll over in bed, cough and talk, and their overall wellbeing. The total score ranges from 0 to 30 . Greater scores represent greater motor limitations ${ }^{13}$.

\section{Motor function measurement (MFM)}

The MFM assesses the functional abilities of individuals with neuromuscular diseases. It contains the following domains: D1 - transfers and standing up; D2 - axial and proximal motor function; and D3 - distal motor function. The scores are based on the individuals' ability to perform the activity without assistance. The final score is calculated as a percentage. Greater percentages represent better functional abilities ${ }^{14}$.

\section{Cardiorespiratory parameters}

The following cardiorespiratory parameters were assessed before, during and after the active sitting test: SBP, DBP, HR, f and oxygen saturation. The SBP and DBP were verified indirectly in each individual's left arm, in line with the recommendations of the Seventh Brazilian Guidelines for Hypertension ${ }^{15}$. The HR was recorded using a heart rate monitor (Polar RS 800 CX, Finland). The f was determined by counting breath by breath for one minute. The oxygen saturation was assessed using a digital pulse oximeter (ChoiceMed, MD300C29, China) positioned on the individual's finger.

\section{Heart rate variability}

To analyze HRV, HR was recorded beat-by-beat using a cardiac monitor (Polar RS 800 CX, Polar Electro Oy, Kempele, Finland) before and during the postural change test. The data recorded were transferred to the Polar Precision Performance software and a series of $256 \mathrm{RR}$ intervals ${ }^{8}$ at rest and during postural change were consider in the analysis on each individual. Digital and manual filtering were used to eliminate premature ectopic beats and artefacts, and only series in which more than $95 \%$ of the beats were sinus beats were included in this study ${ }^{16}$. The HRV was analyzed in the time and frequency domains using the Kubios HRV software ${ }^{16}$.

In the time domain, the following indices were calculated ${ }^{8}$ : a) root-mean square of the differences between adjacent normal RR intervals, expressed in milliseconds (ms) (RMSSD); b) percentage of adjacent RR intervals with a difference in duration greater than $50 \mathrm{~ms}$ (PNN50); c) standard deviation of all normal RR intervals recorded in a time interval, expressed in ms (SDNN); d) SD1: standard deviation 1; and e) SD2: standard deviation 2 .

In the frequency domain, the following indices were calculated using fast Fourier transforms (FFTs): a) low-frequency spectral component (LF: 0.04 to $0.15 \mathrm{~Hz}$ ); b) high-frequency spectral component (HF: 0.15 to $0.4 \mathrm{~Hz}$ ). Both were calculated in squared milliseconds $\left(\mathrm{ms}^{2}\right)$ and normalized units (nu).

\section{Data analysis}

A descriptive statistical method was used for sample characterization, in which the results were expressed as means, standard deviations and percentages. The normality of the data was tested using the Shapiro-Wilk test. Differences between the control and DMD groups were compared using Student's t test or the Mann-Whitney test, according to the normality of the data.

To identify HRV and cardiorespiratory parameters at rest and in response to postural change in the two groups, repeated-measurement analysis of variance (ANOVA) was used. Effect size was analyzed using partial eta squared. The significance level was set at 5\%. The Statistical Package for the Social Sciences (SPSS) software, version 20.0, was used for the analysis.

\section{RESULTS}

Table 1 presents the participants' characteristics. The adolescents with DMD presented lower weight, height, resting SBP and resting oxygen saturation than the healthy adolescents. Conversely, higher resting HR was observed among the adolescents with DMD. Regarding the motor limitation, lower-limb function and functional ability of the adolescents with DMD included in this study, the average score calculated from the EK scale was relatively low (9.3 out of 30), thus indicating lower motor limitations. However, the scores from the Vignos scale showed that most of our population were able to walk only with assistance or walk independently with leg braces. Furthermore, a greater number of people scored D3 in the MFM, which indicated that they presented lower distal motor function. It is also important to highlight that 14 adolescents in the DMD group were using a wheelchair (82\%).

Table 2 presents a comparative time and frequency domain analysis on HRV between the DMD and CG. Reduced SDNN, RMSSD, PNN50, HFms ${ }^{2}$, HFnu, SD1 and SD1/SD2 were observed among the adolescents with $\mathrm{DMD}$, compared with the CG. Conversely, increased LFnu and LF/HF ratio were observed in the DMD group. No significant differences between groups were observed in relation to $\mathrm{LFms}^{2}$ and SD2.

Table 3 presents a comparison of cardiorespiratory parameters assessed at rest (M1), during the active sitting test (M2) and after the active sitting test (M3) in the DMD and CG. Differences between the groups were observed with regard to the participants' oxygen saturation, HR and $\mathrm{f}(\mathrm{p}<0.05)$; in relation to analysis times for all variables except the oxygen saturation ( $p=0.869)$; and in relation to the interaction effect between group and time for SBP and DBP $(p<0.000)$.

Table 4 shows a comparative time domain analysis on HRV assessed at rest (M1) and during the active sitting test (M2) in the DMDG and CG. Differences between the groups were observed for all time domain analyses on $\operatorname{HRV}(\mathrm{p}<0.05)$. 
Table 1. Comparison of the characteristics of the variables between DMDG and CG.

\begin{tabular}{|c|c|c|c|}
\hline & DMDG & CG & $p$ value \\
\hline Vignos (score) & $6.42 \pm 2.00$ & - & - \\
\hline EK (score) & $9.34 \pm 4.70$ & - & - \\
\hline MFM D1 (\%) & $11.72 \pm 19.46$ & - & - \\
\hline MFM D2 (\%) & $69.73 \pm 21.40$ & - & - \\
\hline MFM D3 (\%) & $83.16 \pm 11.55$ & - & - \\
\hline MFM total (\%) & $48.84 \pm 16.39$ & - & - \\
\hline Age years) $^{b}$ & $15.00 \pm 3.00$ & $14.54 \pm 2.15$ & 0.345 \\
\hline Weight (kg)a & $53.32 \pm 10.27$ & $64.04 \pm 15.27$ & $0.003^{*}$ \\
\hline Height $(m)^{a}$ & $1.54 \pm 0.11$ & $1.67 \pm 0.09$ & $0.000 *$ \\
\hline $\mathrm{BMI}\left(\mathrm{kg} / \mathrm{m}^{2}\right)^{\mathrm{a}}$ & $22.51 \pm 4.18$ & $22.60 \pm 4.31$ & 0.980 \\
\hline $\mathrm{SBP}(\mathrm{mmHg})^{a}$ & $98.85 \pm 8.41$ & $107.41 \pm 12.37$ & $0.004^{\star}$ \\
\hline $\mathrm{DBP}(\mathrm{mmHg})^{\mathrm{a}}$ & $63.18 \pm 10.40$ & $66.77 \pm 8.71$ & 0.154 \\
\hline $\mathrm{HR}(\mathrm{bpm})^{\mathrm{a}}$ & $88.40 \pm 12.07$ & $75.74 \pm 13.54$ & $0.000 *$ \\
\hline $\mathrm{SatO}_{2}(\%)^{\mathrm{b}}$ & $97.53 \pm 0.69$ & $97.96 \pm 0.75$ & $0.013^{*}$ \\
\hline$f(r p m)^{b}$ & $21.66 \pm 4.96$ & $19.64 \pm 4.07$ & 0.171 \\
\hline
\end{tabular}

a Student's t test: mean \pm standard deviation; ${ }^{\mathrm{B}}$ Mann-Whitney: median \pm interquartile range; DMDG: Duchenne muscular dystrophy group; CG: control group; EK: Egen classification scale; MFM: motor function measurement scale; \%: percentage; BMI: body mass index; SBP: systolic blood pressure; DBP: diastolic blood pressure; HR: heart rate; $\mathrm{SatO}_{2}$ : oxygen saturation; f: Respiratory frequency; $\mathrm{kg}$ : kilogram; $\mathrm{m}$ : meters; $\mathrm{m}^{2}$ : square meters; $\mathrm{mmHg}$ : millimeters of mercury; bpm: beats per minute; rpm: repetitions per minute; * ${ }^{p}$ value statistically significant.

Table 2. Comparison of linear indices in time and frequency domains between control and DMD groups at rest.

\begin{tabular}{|c|c|c|c|}
\hline & DMDG & $\mathrm{CG}$ & $p$ value \\
\hline SDNN ${ }^{b}$ & $37.60 \pm 14.50$ & $49.60 \pm 30.80$ & $0.016 *$ \\
\hline $\mathrm{RMSSD}^{\mathrm{a}}$ & $27.32 \pm 12.46$ & $49.38 \pm 22.55$ & $0.000 *$ \\
\hline $\mathrm{pNN50}$ & $4.90 \pm 11.20$ & $35.90 \pm 30.40$ & $0.000 *$ \\
\hline LFms $^{2 b}$ & $521.00 \pm 690.00$ & $703.00 \pm 861.00$ & 0.469 \\
\hline LFnu $^{a}$ & $66.37 \pm 12.08$ & $50.77 \pm 19.48$ & $0.001 *$ \\
\hline $\mathrm{HFms}^{2 \mathrm{~b}}$ & $294.00 \pm 407.00$ & $891.00 \pm 1143.00$ & $0.005^{*}$ \\
\hline $\mathrm{HFnu}^{\mathrm{a}}$ & $32.74 \pm 11.72$ & $48.87 \pm 19.29$ & $0.000 *$ \\
\hline $\mathrm{LF} / \mathrm{HF}^{\mathrm{b}}$ & $1.86 \pm 1.59$ & $0.91 \pm 1.93$ & $0.003^{*}$ \\
\hline $\mathrm{SD} 1^{\mathrm{a}}$ & $19.34 \pm 8.82$ & $34.97 \pm 15.98$ & $0.000 *$ \\
\hline $\mathrm{SD} 2^{\mathrm{b}}$ & $48.40 \pm 21.50$ & $61.40 \pm 39.40$ & 0.103 \\
\hline $\mathrm{SD} 1 / \mathrm{SD} 2^{\mathrm{b}}$ & $0.36 \pm 0.18$ & $0.56 \pm 0.26$ & $0.005^{\star}$ \\
\hline
\end{tabular}

a Student's t test: mean \pm standard deviation; ${ }^{b}$ Mann-Whitney: median \pm interquartile range; DMDG: Duchenne muscular dystrophy; CG: control group; SDNN: standard deviation of all normal RR intervals, expressed in milliseconds; RMSSD: root mean square of the differences between adjacent normal RR intervals, expressed in milliseconds; pNN50: percentage of adjacent RR intervals with duration difference greater than 50 milliseconds; LF: low-frequency component; HF: high-frequency component; nu: normalized units; $\mathrm{ms}^{2}$ : milliseconds squared; SD1: standard deviation 1 of the Poincaré plot; SD2: standard deviation 2 of the Poincaré plot; * $p$ value statistically significant.

Table 3. Repeated-measurement ANOVA comparing cardiorespiratory parameters for DMD and control groups, at rest (M1), during postural change (M2) and after postural change (M3).

\begin{tabular}{|c|c|c|c|c|c|c|}
\hline Variables & DMDG & CG & & & & \\
\hline & \multicolumn{2}{|c|}{ Mean \pm SD } & Effect & $F$ & $p$-value & Partial eta-squared \\
\hline \multicolumn{7}{|l|}{ SBP } \\
\hline M1 & $98.85 \pm 8.41$ & $107.41 \pm 12.37$ & Group & 0.061 & 0.806 & 0.001 \\
\hline M2 & $110.59 \pm 14.59 *$ & $108.38 \pm 10.98$ & Time & 5.714 & $0.020 *$ & 0.091 \\
\hline M3 & $108.00 \pm 12.72^{\star}$ & $104.19 \pm 11.48$ & Group $\times$ time & 24.35 & $0.000 *$ & 0.299 \\
\hline \multicolumn{7}{|l|}{ DBP } \\
\hline M1 & $63.18 \pm 10.40$ & $66.77 \pm 8.71$ & Group & 3.011 & 0.088 & 0.050 \\
\hline M2 & $76.77 \pm 12.29 *$ & $69.19 \pm 7.53$ & Time & 28.985 & $0.000 *$ & 0.337 \\
\hline
\end{tabular}


Table 3. Cont.

\begin{tabular}{|c|c|c|c|c|c|c|}
\hline Variables & DMDG & CG & & & & \\
\hline M3 & $74.85 \pm 12.19 *$ & $67.09 \pm 7.39$ & Group $\times$ time & 25.908 & $0.000 *$ & 0.312 \\
\hline \multicolumn{7}{|l|}{$\mathrm{SatO}_{2}$} \\
\hline M1 & $97.53 \pm 0.69$ & $97.96 \pm 0.75$ & Group & 17.562 & $0.000 *$ & 0.236 \\
\hline M2 & $97.29 \pm 0.91$ & $98.06 \pm 0.44$ & Time & 0.027 & 0.869 & 0.000 \\
\hline M3 & $97.59 \pm 0.63$ & $97.93 \pm 0.77$ & Group $\times$ time & 0.193 & 0.662 & 0.003 \\
\hline \multicolumn{7}{|l|}{ HR } \\
\hline M1 & $88.40 \pm 12.07$ & $75.74 \pm 13.54$ & Group & 36.751 & $0.000 *$ & 0.392 \\
\hline M2 & $113.18 \pm 13.35^{*}$ & $84.90 \pm 12.56^{*}$ & Time & 13.534 & $0.001^{*}$ & 0.192 \\
\hline M3 & $93.29 \pm 14.94 \#$ & $79.87 \pm 11.84^{*} \#$ & Group $\times$ time & 0.105 & 0.747 & 0.002 \\
\hline \multicolumn{7}{|l|}{ f } \\
\hline M1 & $21.66 \pm 4.96$ & $19.64 \pm 4.07$ & Group & 5.897 & $0.018^{*}$ & 0.094 \\
\hline M2 & $21.22 \pm 4.00$ & $18.61 \pm 3.86$ & Time & 8.006 & $0.006^{*}$ & 0.123 \\
\hline M3 & $20.29 \pm 3.94$ & $18.32 \pm 3.79$ & Group $\times$ time & 0.045 & 0.834 & 0.001 \\
\hline
\end{tabular}

* Difference compared with M1; \# Difference compared with M2; DMDG: Duchenne muscular dystrophy group; CG: control group; SD: standard deviation; M1: at rest; M2: during postural change; M3: after postural change; SBP: systolic blood pressure; DBP: diastolic blood pressure; SatO ${ }_{2}$ oxygen saturation; HR: heart rate; f: respiratory rate; * $p$ value statistically significant.

Table 4. Repeated-measurement ANOVA comparing HRV in the DMDG and control groups at rest (M1) and during postural change (M2).

\begin{tabular}{|c|c|c|c|c|c|c|}
\hline Variables & DMDG & CG & & & & \\
\hline & \multicolumn{2}{|c|}{ Mean \pm SD } & Effect & $\mathrm{F}$ & $p$-value & Partial eta-squared \\
\hline SDNN & & & Group & 8.147 & $0.006^{*}$ & 0.127 \\
\hline M1 & $39.87 \pm 13.22$ & $50.99 \pm 19.29$ & Time & 29.429 & $0.000 *$ & 0.344 \\
\hline M2 & $50.64 \pm 22.56^{\star}$ & $64.23 \pm 17.53^{\star}$ & Group $\times$ time & 0.310 & 0.580 & 0.006 \\
\hline RMSSD & & & Group & 19.294 & $0.000 *$ & 0.256 \\
\hline M1 & $27.32 \pm 12.46$ & $49.38 \pm 22.55$ & Time & 10.978 & $0.002^{\star}$ & 0.164 \\
\hline M2 & $26.12 \pm 12.72$ & $41.88 \pm 17.52^{\star}$ & Group $\times$ time & 5.755 & $0.020 *$ & 0.093 \\
\hline PNN50 & & & Group & 12.579 & $0.001 *$ & 0.183 \\
\hline M1 & $9.36 \pm 10.19$ & $29.87 \pm 20.12$ & Time & 0.015 & 0.904 & 0.000 \\
\hline M2 & $8.49 \pm 9.69$ & $29.68 \pm 48.11$ & Group $\times$ time & 0.006 & 0.938 & 0.000 \\
\hline SD1 & & & Group & 19.296 & $0.000^{\star}$ & 0.256 \\
\hline M1 & $19.34 \pm 8.82$ & $34.97 \pm 15.98$ & Time & 11.019 & $0.002^{\star}$ & 0.164 \\
\hline M2 & $18.49 \pm 9.00$ & $29.65 \pm 12.41^{\star}$ & Group $\times$ time & 5.791 & $0.019 *$ & 0.094 \\
\hline SD2 & & & Group & 5.621 & $0.021^{\star}$ & 0.091 \\
\hline M1 & $52.70 \pm 17.17$ & $62.40 \pm 24.30$ & Time & 37.036 & $0.000 *$ & 0.398 \\
\hline M2 & $69.01 \pm 30.99 *$ & $85.45 \pm 22.86^{\star}$ & Group $\times$ time & 1.085 & $0.302^{\star}$ & 0.019 \\
\hline SD1/SD2 & & & Group & 21.383 & $0.000^{*}$ & 0.276 \\
\hline M1 & $0.36 \pm 0.10$ & $0.56 \pm 0.19$ & Time & 75.651 & $0.000 *$ & 0.575 \\
\hline M2 & $0.27 \pm 0.08 *$ & $0.33 \pm 0.10 *$ & Group $\times$ time & 13.528 & $0.001 *$ & 0.195 \\
\hline
\end{tabular}

* Difference compared with M1; DMDG: Duchenne muscular dystrophy group; CG: control group; SD: standard deviation; M1: at rest; M2: during postural change; SDNN: standard deviation of all normal RR intervals, expressed in milliseconds; RMSSD: square root of the square mean of the differences between adjacent normal RR intervals, expressed in milliseconds; pNN50: percentage of adjacent RR intervals with duration difference greater than 50 milliseconds; SD1: standard deviation 1 of the Poincaré plot; SD2: standard deviation 2 of the Poincaré plot; * p value statistically significant.

Differences in relation to time periods were observed for all time domain analyses on HRV $(\mathrm{p}<0.05)$, except for the PNN50 index $(p=0.904)$. Interactions between group and time were observed for the indices RMSSD, SD1, SD2 and SD1/SD2.

Table 5 presents a comparative frequency domain analysis on HRV assessed at rest (M1) and during the active sitting test (M2) in the DMDG and CG. Differences between groups were observed for all frequency domain analyses on HRV ( $p$ $<0.05)$, except for LF/HF ( $p=0.793)$. Differences in relation to time period and interaction between group and time were observed for LFms ${ }^{2}$, LFnu and HFnu $(\mathrm{p}<0.05)$. No significant effects were observed for LF/HF ( $p>0.05)$. 
Table 5. Repeated-measurement ANOVA comparing HRV indices in the frequency domain for DMDG and CG, at rest (M1) and during postural change (M2).

\begin{tabular}{|c|c|c|c|c|c|c|}
\hline Variables & DMDG & CG & & & & \\
\hline & \multicolumn{2}{|c|}{ Mean \pm SD } & Effect & $\mathrm{F}$ & $p$-value & Partial eta-squared \\
\hline LFms $^{2}$ & & & Group & 4.659 & $0.035^{*}$ & 0.077 \\
\hline M1 & $744.14 \pm 640.21$ & $874.70 \pm 706.05$ & Time & 9.203 & $0.004^{*}$ & 0.141 \\
\hline M2 & $831.03 \pm 869.10$ & $1516.12 \pm 1091.50 *$ & Group $\times$ time & 5.335 & $0.025^{*}$ & 0.087 \\
\hline LFnu & & & Group & 4.818 & $0.032 *$ & 0.079 \\
\hline M1 & $66.37 \pm 12.08$ & $50.77 \pm 19.48$ & Time & 14.495 & $0.000 *$ & 0.206 \\
\hline M2 & $66.36 \pm 11.68$ & $66.83 \pm 15.94^{\star}$ & Group $\times$ time & 14.548 & $0.000 *$ & 0.206 \\
\hline $\mathrm{HFms}^{2}$ & & & Group & 14.807 & $0.000 *$ & 0.209 \\
\hline M1 & $385.29 \pm 328.03$ & $952.58 \pm 824.37$ & Time & 1.813 & 0.184 & 0.031 \\
\hline M2 & $374.81 \pm 311.98$ & $771.61 \pm 510.35$ & Group $\times$ time & 1.438 & 0.236 & 0.025 \\
\hline HFnu & & & Group & 15.989 & $0.000^{*}$ & 0.222 \\
\hline M1 & $32.74 \pm 11.72$ & $48.87 \pm 19.29$ & Time & 56.774 & $0.000^{*}$ & 0.503 \\
\hline M2 & $33.11 \pm 11.35$ & $33.02 \pm 15.80^{\star}$ & Group $\times$ time & 5.228 & $0.026^{*}$ & 0.085 \\
\hline LF/HF & & & Group & 0.070 & 0.793 & 0.001 \\
\hline M1 & $2.49 \pm 1.63$ & $1.49 \pm 1.27$ & Time & 2.418 & 0.126 & 0.041 \\
\hline M2 & $2.42 \pm 1.30$ & $3.87 \pm 7.98$ & Group $\times$ time & 2.757 & 0.102 & 0.047 \\
\hline
\end{tabular}

*Difference in relation to M1; DMD: Duchenne muscular dystrophy; CG: control group; SD: standard deviation; M1: at rest; M2: during postural change; LF: lowfrequency component; HF: high-frequency component; nu: normalized units; $\mathrm{ms}^{2}$ : milliseconds squared.

\section{DISCUSSION}

Overall, the adolescents with DMD participating in this study were not in the advanced phase of the disease. However, greater difficulty regarding distal limb motor function, medium difficulty regarding axial and proximal limb motor function and lower difficulty in relation to the standing position and transference were observed. This may indicate progression of the DMD in this population. Progression of DMD is associated not only with motor dysfunction ${ }^{17}$ but also with greater chances of developing myocardiopathies, respiratory problems and notable autonomic modulation changes ${ }^{3,4,17,18 i d a d e} 16,75( \pm 6,9$. This emphasizes the importance of monitoring these factors in individuals with DMD.

Regarding the cardiorespiratory variables and autonomic modulation, our data suggested that the adolescents with DMD showed reduced SBP, oxygen saturation, parasympathetic modulation and overall variability, along with greater $\mathrm{HR}$, f, and sympathetic modulation, compared with healthy adolescents. Overall, the active sitting test increased sympathetic modulation and decreased parasympathetic modulation in both the healthy adolescents and those with DMD. However, this study indicated that the changes in the ANS during the active sitting test were smaller in the DMD group than in the CG.

In terms of the cardiorespiratory variables, our results were in line with those of Massood et al. ${ }^{19}$, who reported that resting blood pressure in children and adolescents with DMD was lower. Reduced resting SBP and oxygen saturation, along with greater resting HR observed in the DMD, may be potentially explainable in terms of the mobility restrictions, reduction in muscle tonus, reduction in peripheral resistance and lower fluid intake that are observed in this population. These factors contribute to intravascular volume reduction, hypotension and HR increase, as compensatory responses for improving the blood volume in the heart ${ }^{19}$. Respiratory changes, such as increases in $\mathrm{f}$ and decreases in oxygen saturation in the DMD group might be associated with advances in these individuals' neuromuscular disease, in which the consequences would include ineffective coughing and hypoventilation ${ }^{20}$. Individuals with respiratory complications while sleeping present higher chances of experiencing apnea and hypopnea, and consequently decreased oxygen saturation ${ }^{20}$.

As reported above, our data suggested that there were differences in autonomic modulation between the adolescents with DMD and the healthy adolescents. The HRV indices in the time and frequency domain RMSSD, PNN50, SD1, HFms ${ }^{2}$, HFnu and SD1/SD2 were reduced in the adolescents with DMD. This suggests a reduction in parasympathetic modulation. The HRV indices SDNN and SD1 were lower in the DMD group, which indicates a reduction in the global modulation in this population.

Reduced parasympathetic and global modulation in individuals with DMD had already been reported in the literature $^{3,5}$ but the way that autonomic function changes in patients with Duchenne muscular dystrophy (DMD. Autonomic alterations may be considered to be a predictor of cardiovascular and metabolic health in the overall population $^{8,21}$. The decreased parasympathetic and global modulation observed in individuals with DMD contribute to 
increased mortality and morbidity in this population ${ }^{8}$ This emphasizes the importance of using efficient treatments aimed at improving the autonomic responses to different stimuli, since this can reduce the cardiovascular and overall risk among individuals with DMD.

The resting HRV indices analyzed in the frequency domain (LFnu and LF/HF ratio) were found to be higher in the adolescents with DMD than in the CG. These data, in association with the reductions in parasympathetic and global modulation, suggested that there was an increase in sympathetic modulation in these adolescents with DMD. It was previously suggested that the alterations in sympathetic autonomic modulation observed in individuals with DMD might be associated with the development of heart failure in this population ${ }^{9}$. However, the sympathetic representativity of the LF index remains a matter of debate. It has been suggested that parasympathetic activation might influence the LF index by up to $50 \%^{22}$. Thus, studies aimed at evaluating the autonomic sympathetic modulation in individuals with DMD via directive measures would be important to confirm our findings.

During the active sitting test, greater increases in the SBP, DBP, HR and $f$ were observed in adolescents with DMD, compared with the CG. These might indicate inadequate adaptation of the cardiorespiratory system and might be associated with the autonomic dysfunctions reported in adolescents with DMD. Regarding the HRV, our data suggested that there was a reduction in the response from the time domain indices of HRV (SDNN, RMSSD, SD1, SD2 and SD1/SD2) during the active sitting test performed by the adolescents with DMD. Similar results were observed with regard to the frequency domain indices of HRV ( $\mathrm{LFms}^{2}$, LFnu and HFnu). No differences in the $\mathrm{HFms}^{2}$ and LF/HF responses to the active sitting test were observed either in the DMD or in the CG. This suggested that the adolescents with DMD had reductions in the parasympathetic and global modulation responses to the active sitting test.

To the best of our knowledge, this was the first study aimed at identifying the autonomic modulation and cardiorespiratory variables at rest and during the active sitting test performed by adolescents with DMD. Analysis on HRV and postural change has been considered to be an effective method for assessing the autonomic modulation in different population. This might be considered to be a strong point of this study.

Our results are in accordance with the initial hypothesis of this study, i.e. that adolescents with DMD would show reduced autonomic modulation and increased cardiorespiratory response to the active sitting test, compared with healthy adolescents. This information identifies a new perspective about the behavior of the ANS in adolescents with DMD during the active sitting test. Postural change is commonly undertaken by adolescents with DMD during their rehabilitation care. Understanding the matters raised by this study may assist in evaluations and guide strategies for monitoring adolescents with DMD during their rehabilitation sessions.

We conclude that adolescents with DMD present reductions in their parasympathetic and global autonomic modulation, either at rest or in response to the active sitting test. Alterations in cardiorespiratory parameters either at rest or in response to the active sitting test were also observed in adolescents with DMD. Early identification of the autonomic and cardiorespiratory dysfunctions in individuals with DMD may help in preventing complications and improving the prognosis for this population.

\section{REFERENCES}

1. Van Westering TLE, Betts CA, Wood MJA. Current understanding of molecular pathology and treatment of cardiomyopathy in duchenne muscular dystrophy. Molecules. 2015 May 15;20(5):8823-55. https:// doi.org/10.3390/molecules20058823

2. Falzarano MS, Scotton C, Passarelli C, Ferlini A. Duchenne muscular dystrophy: from diagnosis to therapy. Molecules. 2015 Oct 7;20(10):18168-84. https://doi.org/10.3390/molecules201018168

3. Inoue M, Mori K, Hayabuchi Y, Tatara K, Kagami S. Autonomic function in patients with Duchenne muscular dystrophy. Pediatr Int. 2009 Feb 23;51(1):33-40. https://doi.org/10.1111/j.1442-200X.2008.02656.x

4. Bachur CK, Garcia MH, Bernardino CA, Requel RC, Bachur JA. Analysis of cardiac exams: electrocardiogram and echocardiogram use in Duchenne muscular dystrophies. Fisioter Mov. 2014 Sep;27(3):42936. https://doi.org/10.1590/0103-5150.027.003.A014

5. Dhargave P, Nalini A, Abhishekn HA, Meghana A, Nagarathna R, Raju TR, et al. Assessment of cardiac autonomic function in patients with Duchene muscular dystrophy using short term heart rate variability measures. Eur J Paediatr Neurol. 2014 May 1;18(3):317-20. https:// doi.org/10.1016/j.ejpn.2013.12.009

6. Mercuri E, Muntoni F. Muscular dystrophies. Lancet. 2013 Mar 9;381(9869):845-60. https://doi.org/10.1016/S0140-6736(12)61897-2
Echocardiographic and electrocardiographic findings of cardiomyopathy in Duchenne and Becker-Kiener muscular dystrophies. Pediatr Cardiol. 2005 Jan-Feb;26(1):66-72. https://doi. org/10.1007/s00246-004-0689-2

8. Vanderlei LCM, Pastre CM, Hoshi RA, Carvalho TD, Godoy MF. Noções básicas de variabilidade da frequência cardíaca e sua aplicabilidade clínica. Braz J Cardiovasc Surg. 2009 Jun;24(2):205-17. https://doi. org/10.1590/S0102-76382009000200018

9. da Silva TD, Massetti T, Crocetta TB, de Mello Monteiro CB, Carll A, Vanderlei LCM, et al. Heart rate variability and cardiopulmonary dysfunction in patients with Duchenne muscular dystrophy: a systematic review. Pediatr Cardiol. 2018 Jun;39(5):869-83. https:// doi.org/10.1007/s00246-018-1881-0

10. Giacon TR, Vanderlei FM, Christofaro DGD, Vanderlei LCM. Impact of diabetes type 1 in children on autonomic modulation at rest and in response to the active orthostatic test. PLoS One. 2016 Oct 27;11(10):e0164375. https://doi.org/10.1371/journal.pone.0164375

11. Moura-Tonello SCG, Takahashi ACM, Francisco CO, Lopes SLB, Del Vale AM, Borghi-Silva A, et al. Influence of type 2 diabetes on symbolic analysis and complexity of heart rate variability in men. Diabetol Metab Syndr. 2014 Feb 1;6(1):13. https://doi. org/10.1186/1758-5996-6-13 
12. Vignos Jr PJ, Spencer Jr GE, Archibald KC. Managemment of progressive muscular dystrophy of childhood. JAMA. 1963 Apr 13;184(2):89-96. https://doi.org/10.1001/ jama.1963.03700150043007

13. Martinez JAB, Brunherotti MA, Assis MR, Sobreira CFDR. Validação da escala motora funcional EK para a língua portuguesa. Rev Assoc Med Bras (1992). 2006 Oct;52(5):347-51. https://doi.org/10.1590/S010442302006000500024

14. Iwabe C, Miranda-Pfeilsticker BH, Nucci A. Motor function measure scale: portuguese version and reliability analysis. Braz J Phys Ther. 2008 Oct;12(5):417-24. https://doi.org/10.1590/S141335552008000500012

15. Malachias MVB, Souza WKSB, Plavnik FL, Rodrigues CIS, Brandão AA, Neves MFT, et al. $7^{a}$ Diretriz brasileira de hipertensão arterial. Arq Bras Cardiol. 2016 Sep;107(3):1-83.

16. Catai AM, Pastre CM, Godoy MF, da Silva E, Takahashi ACM, Vanderlei LCM. Heart rate variability: are you using it properly? Standardisation checklist of procedures. Braz J Phys Ther. 2020 Mar-Apr;24(2):91-102. https://doi.org/10.1016/j.bjpt.2019.02.006

17. Okama LO, Queiroz PD, Spina LR, Miranda MBL, Curtarelli MB, Faria Júnior M, et al. Avaliação funcional e postural nas distrofias musculares de Duchenne e Becker. ConScientiae Saúde. 2010;9(4):649-58. https://doi.org/10.5585/conssaude.v9i4.2413

18. Thomas TO, Jefferies JL, Lorts A, Anderson JB, Gao Z, Benson DW, et al. Autonomic dysfunction: a driving force for myocardial fibrosis in young Duchenne muscular dystrophy patients? Pediatr Cardiol. 2015 Mar;36(3):561-8. https://doi.org/10.1007/s00246-014-1050-z

19. Masood SA, Kazmouz S, Heydemann P, Li H, Kenny D. Underrecognition of low blood pressure readings in patients with Duchenne muscular dystrophy. Pediatr Cardiol. 2015 Oct;36(7):1489-94. https:// doi.org/10.1007/s00246-015-1191-8

20. Fonseca JG, Machado MJF, Ferraz CLMS. Distrofia muscular de Duchenne: complicações respiratórias e seu tratamento. Rev Ciênc Méd (Campinas). 2007 Mar-Apr;16(2):109-20.

21. Silva AKF, Christofaro DGD, Vanderlei FM, Barbosa MPCR, Garner DM, Vanderlei LCM. Association of cardiac autonomic modulation with physical and clinical features of young people with type 1 diabetes. Cardiol Young. 2017 Jan;27(1):37-45. https://doi.org/10.1017/ S1047951116000044

22. Billman GE. The LF/HF ratio does not accurately measure cardiac sympatho-vagal balance. Front Physiol. 2013 Feb 20;4:26. https://doi. org/10.3389/fphys.2013.00026 